\title{
Split laminotomy versus conventional laminotomy: postoperative outcomes in pediatric patients
}

\author{
Elsa V. Arocho-Quinones, MD, ${ }^{1}$ Amie Kolimas, BS, ${ }^{2}$ Peter S. LaViolette, PhD, ${ }^{3}$ \\ Bruce A. Kaufman, MD, ${ }^{1,4}$ Andrew B. Foy, MD, ${ }^{1,4}$ Marike Zwienenberg, MD, ${ }^{5}$ and Sean M. Lew, MD ${ }^{1,4}$ \\ Departments of ${ }^{1}$ Neurosurgery and ${ }^{3}$ Radiology, Medical College of Wisconsin, Milwaukee, Wisconsin; ${ }^{2}$ Chicago College of \\ Osteopathic Medicine, Downers Grove, Illinois; ${ }^{4}$ Department of Neurosurgery, Children's Hospital of Wisconsin, Milwaukee, \\ Wisconsin; and ${ }^{5}$ Department of Neurosurgery, University of California Davis Medical Center, Sacramento, California
}

\begin{abstract}
OBJECTIVE Split laminotomy is a technique for accessing the spinal canal from the posterior midline that minimizes muscle dissection and bone removal. Benefits of this approach in minimizing postoperative pain and muscle atrophy in the adult population have been reported, but pediatric data are limited. Herein, the authors evaluate the benefits of the split laminotomy technique in pediatric patients.
\end{abstract}

METHODS Data obtained in patients who underwent posterior spine surgery at Children's Hospital of Wisconsin for an intradural midline pathology between April 2008 and June 2015 were reviewed retrospectively. Each patient was assigned to one of two groups, the split-laminotomy or conventional-laminotomy group. The primary outcomes assessed were mean daily pain score, total opioid use over a period of 72 hours after surgery, and the degree of paraspinal muscle atrophy and fat infiltration found on short-term (1-4 months) and long-term (1-4 years) follow-up spine MRI studies.

RESULTS A total of 117 patients underwent lumbar-level surgery (83 conventional laminotomy, 34 split laminotomy), and 8 patients underwent thoracic-level surgery (4 in each group). No significant difference in the mean daily pain scores between groups was found. The daily opioid use was significantly lower in the split-laminotomy group on postoperative day 0 (POD0) and POD1 but not on POD2 ( $p=0.01,0.01$, and 0.10 , respectively). The total opioid use over the 72-hour postoperative period was significantly lower in the split-laminotomy group $(p=0.0008)$. The fat/muscle ratio was significantly higher in both the short-term and long-term follow-up periods in the conventional-laminotomy group ( $p=0.01$ and 0.0002 , respectively). The rate of change of paraspinal muscle fat infiltration was significantly lower in the split-laminotomy group than in the conventional-laminotomy group $(p=0.007)$. The incidence of complications was not significantly different between groups ( $p=0.08)$.

CONCLUSIONS This study was of the largest series reported thus far of pediatric patients who underwent split laminotomy and the only controlled study that has involved children. The authors' results reinforce the short-term benefit of split laminotomy in minimizing acute postoperative pain and long-term benefits of decreasing muscle atrophy and fatty degeneration, which are known to be associated with the development of chronic pain and spinal instability. Additional efforts for assessing long-term effects in the development of chronic pain, spinal instability, and spinal deformity are still necessary.

https://thejns.org/doi/abs/10.3171/2017.12.PEDS17368

KEY WORDS split laminotomy; hemilaminotomy; laminectomy; pain control; muscle atrophy; pediatric spine

$\mathrm{S}$ PLIT laminotomy is a technique for accessing the spinal canal from the posterior midline that minimizes the muscle dissection and bone removal associated with more traditional techniques, such as hemilaminotomy, adjacent-level laminotomy, and full laminectomy (Fig. 1). The split laminotomy is particularly well suited for pathologies that require a posterior midline/dorsal ap- proach, such as spinal arachnoid cysts, spinal lipomas, spinal dysraphism, and dorsally located spinal tumors/cysts. Benefits of this approach in minimizing postoperative pain and muscle atrophy in the adult population have been

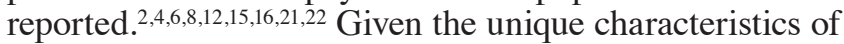
the pediatric spine, split laminotomy might be even more beneficial in pediatric patients, but available data are lim-

ABBREVIATIONS IV = intravenous; OME = oral morphine equivalent; $P O D=$ postoperative day; $P S M=$ paraspinal muscle; $R O I=$ region of interest.

SUBMITTED July 10, 2017. ACCEPTED December 8, 2017.

INCLUDE WHEN CITING Published online March 23, 2018; DOI: 10.3171/2017.12.PEDS17368. 


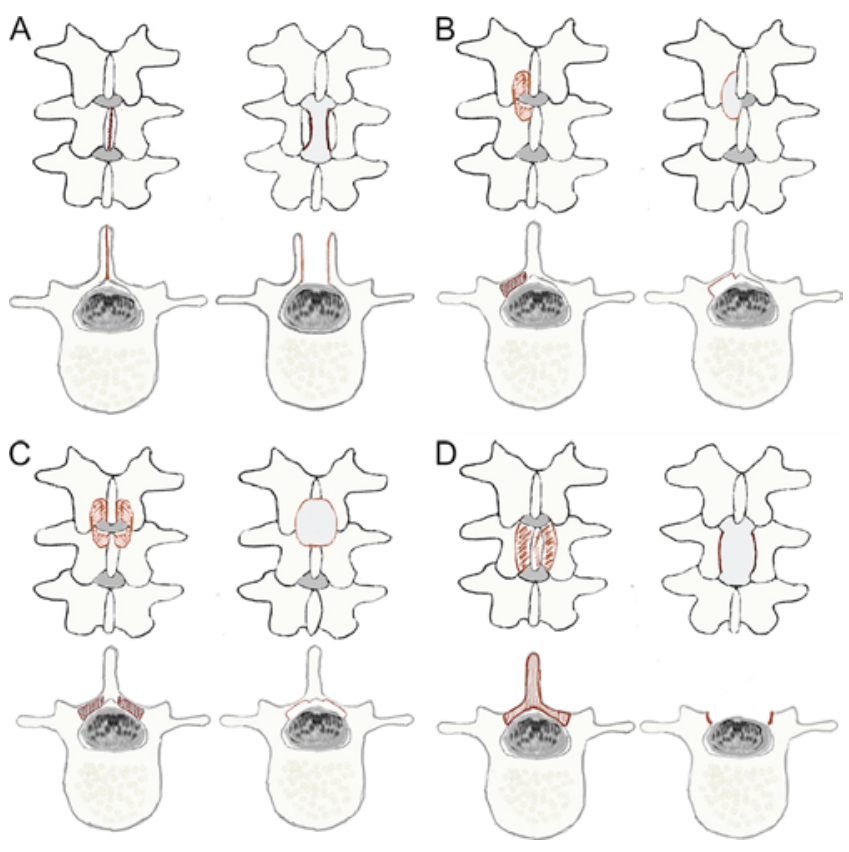

FIG. 1. Schematic representation of bone work in the split laminotomy, hemilaminotomy, and laminectomy approaches. Coronal (upper) and axial (lower) views include a maroon-shaded target region for bone removal (left) and the resulting exposure (right) for the split laminotomy (A), 2-level partial hemilaminotomy (B), 2-level central laminotomy (C), and laminectomy (D). Figure is available in color online only.

ited to those from an uncontrolled case series of 6 patients and a case report of its application in an extensive multilevel exposure for the debulking of a cervicothoracolumbar spinal cord lipoma. ${ }^{3,10}$

The goal of this study was to evaluate the benefits of the split laminotomy technique in pediatric patients by comparing its outcomes (acute postoperative pain control, incidence and degree of paraspinal muscle [PSM] atrophy/ fatty infiltration, and complications) to those of more conventional laminotomy procedures.

\section{Methods \\ Ethical Review/Approval}

This study was evaluated and approved by the Children's Hospital of Wisconsin IRB. A waiver of consent was approved by our IRB given the minimal risk associated with this retrospective chart review study without experimental practices or the need for identifiable patient information.

\section{Population}

We reviewed retrospectively the charts of 125 pediatric patients who underwent posterior spine surgery via conventional laminotomy or split laminotomy at Children's Hospital of Wisconsin between April 2008 and June 2015 (Table 1).

\section{Inclusion Criteria}

Patients of either sex from infancy up to 20 years of age with an intradural midline pathology diagnosis (e.g., spinal lipoma, dorsally located spinal tumor/cyst) were included.

\section{Exclusion Criteria}

Patients who were older than 21 years, had undergone previous surgery at the same level or surgery that spanned more than 2 levels, had a diagnosis of intramedullary spinal cord tumor, and/or had a history of spinal irradiation were excluded.

\section{Patient Allocation}

The pathologies found in the initial cohort included spinal arachnoid cysts, spinal lipomas, and dorsally located intradural extramedullary spinal tumors at a thoracic $(n=$ $8)$ or lumbar $(n=117)$ level. To maintain a homogeneous population, only the patients with a lumbar spinal lipoma who underwent filum terminale sectioning for cord detethering $(n=117)$ were included in the statistical analysis. These patients were assigned to one of two groups accord-

TABLE 1. Population characteristics

\begin{tabular}{|c|c|c|c|c|c|}
\hline Laminotomy Type & Age Range (mos-yrs) & No. of Females/Males & No. of Patients & Spinal Level & Diagnosis \\
\hline \multirow[t]{7}{*}{ Conventional } & \multirow[t]{7}{*}{$2-19$} & \multirow[t]{7}{*}{$44 / 43$} & 1 & $\mathrm{~T} 1-2$ & Tumor \\
\hline & & & 1 & T3-5 & Dermal sinus tract \\
\hline & & & 1 & $\mathrm{~T} 7-8$ & Tumor \\
\hline & & & 1 & $\mathrm{~T} 10-11$ & Tumor \\
\hline & & & 6 & L3-4 & Filum lipoma \\
\hline & & & 41 & L4-5 & Filum lipoma \\
\hline & & & 36 & L5-S1 & Filum lipoma \\
\hline \multirow[t]{7}{*}{ Split } & \multirow[t]{7}{*}{$5-17$} & \multirow[t]{7}{*}{$21 / 17$} & 2 & T3 & Arachnoid cyst \\
\hline & & & 1 & T8-9 & Arachnoid cyst \\
\hline & & & 1 & T12 & Spinal lipoma \\
\hline & & & 3 & L2 & Filum lipoma \\
\hline & & & 11 & L3 & Filum lipoma \\
\hline & & & 16 & L4 & Filum lipoma \\
\hline & & & 4 & L5 & Filum lipoma \\
\hline
\end{tabular}


ing to the surgical strategy used for exposure (i.e., split laminotomy or conventional laminotomy).

\section{Surgical Details}

A total of 4 surgeons in this study (S.M.L., B.A.K., A.B.F., and M.Z.) were identified. All split laminotomy procedures were performed by the same surgeon (the senior author, S.M.L.). The conventional-laminotomy group included some hemilaminectomy procedures and 2-level central laminotomies (Fig. 1).

\section{Split Laminotomy: Operative Technique}

The basics of this technique have been published previously; ${ }^{2-4,6,8,12,15,16,21,22}$ our modifications are noted here. A midline incision is fashioned over the target lumbar lamina. The dissection proceeds to the lumbar fascia, which is split in the midline over the spinous process of the target level. The inferior surface of the midline spinous process/ lamina is dissected subperiosteally with a Penfield no. 1 dissector or up-angled curette to gain access to the epidural space. Then, a split laminotomy is performed using a Midas Rex drill with a Legend B-1 or S-1 dissecting tool (models F2/8TA23 and F3/9TA30, respectively; Medtronic) with a foot plate (model AF03; Medtronic). For adultsized patients with long spinous processes, the most dorsal tip of the spinous process might need to be drilled down or shortened with rongeurs to allow placement of the longer S-1 bit with the foot plate in the sublaminar space. The paraspinal musculature is left attached to the lamina. One or 2 laminar distractors (Inge lamina spreaders, $170 \mathrm{~mm}$; Medline) are deployed slowly to retract the laminar edges. A Penfield no. 1 dissector is first inserted between the split laminar edges and rotated to initiate the distraction. A laminar distractor is then placed with care to ensure that the tips are between the laminar edges and not merely between the split spinous process halves before spreading. The bony exposure achieved is typically $8-12 \mathrm{~mm}$ wide.
A microscope is brought into the field for the intradural portion. The dura mater is closed using nonpenetrating titanium clips (AnastoClip AC closure system, model E4000-07; LeMaitre). ${ }^{7}$ The laminae are reapproximated by closing the lumbar fascia (or, in younger children, sewing the cartilaginous or bony split spinous process together) (Figs. 2 and 3 and Video 1).

VIDEO 1. Split laminotomy approach for filum lipoma sectioning. In this video, Dr. Lew describes the L-4 split laminotomy for filum lipoma sectioning in a 5-month-old patient. Copyright Medical College of Wisconsin. Published with permission. Click here to view.

This technique can be used for multiple consecutive levels. ${ }^{10}$ The laminar distractors can be moved up and down the exposure as needed to work at a particular level.

\section{Pain Scores}

Developmentally appropriate pain scores were recorded several times per day for each patient in the immediate postoperative period and at discharge. Mean daily pain scores in the first 72 hours after surgery were compared across the groups. The following scales were used: the face, legs, activity, cry, and consolability (commonly called FLACC) scale; the verbal numerical rating scale; the face pain scale; and the verbal descriptor scale.,111,19,20

\section{Acute Pain Control: Opiate Consumption}

All the surgeons followed a similar multimodal pain management approach. Weight- and age-appropriate oral or intravenous (IV) acetaminophen and IV ketorolac or ibuprofen (when oral intake was tolerated) was administered on a scheduled basis for the first 24-48 hours. Opioid medications were administered as needed for breakthrough pain. A pain service was used for patients who required a patient-controlled analgesia pump.

Various opiates, including oxycodone, IV morphine sulfate, IV hydromorphone, and IV fentanyl, were used
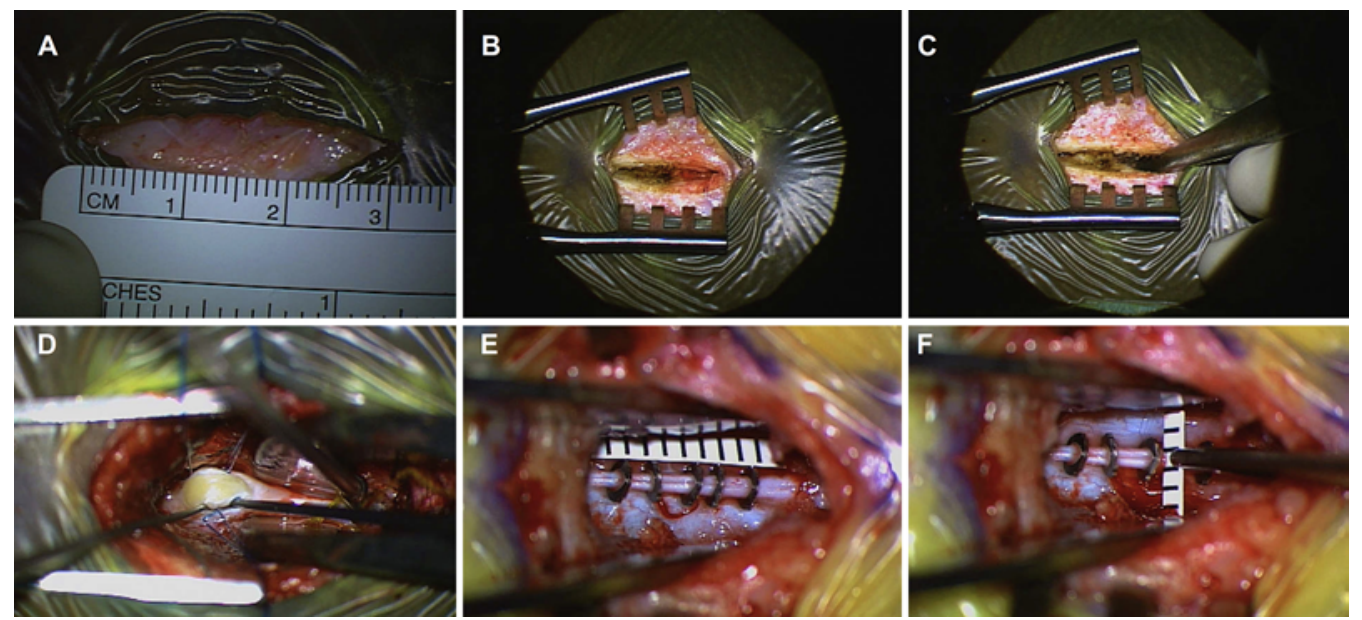

FIG. 2. Split laminotomy technique. A: A midline incision is fashioned over the target lumbar lamina. B: The lumbar fascia is split in the midline over the spinous process of the target level. C: The epidural space is accessed by dissecting in a subperiosteal fashion in the inferior midline. A split laminotomy is performed using a Midas Rex drill (small B-1 or large S-1 dissecting tool with foot plate). The paraspinal musculature is left attached to the laminae. D: The laminar retractors reach almost down to the dura to prevent bone cracks. A filum lipoma is visualized through the dural opening. $\mathrm{E}$ and F: The dura is closed using AnastoClips. ${ }^{7}$ The width of exposure with the split laminotomy ranges from approximately 0.8 to $1 \mathrm{~cm}$. Figure is available in color online only. 

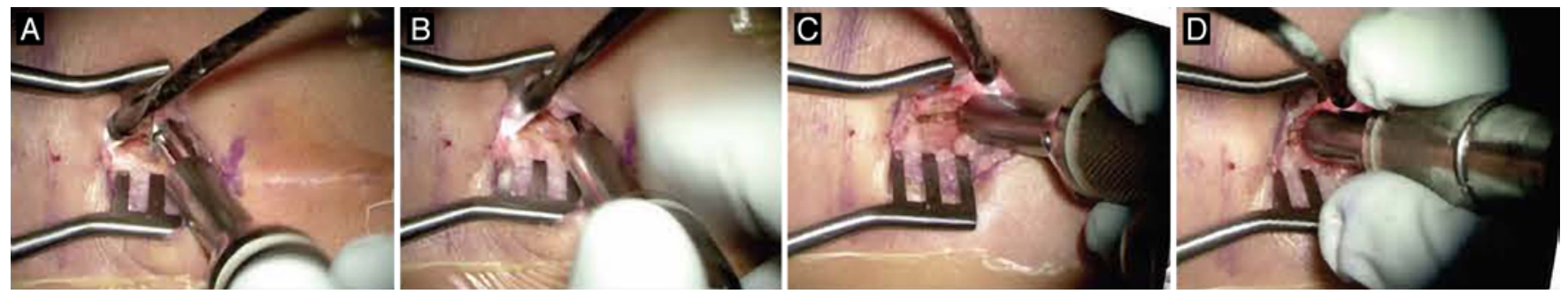

FIG. 3. Positioning of a Midas Rex drill for the split laminotomy approach. A split laminotomy is performed using a Midas Rex drill with a Legend B-1 or S-1 dissecting tool with a foot plate. A and B: Movements made to position the foot plate in the sublaminar/ epidural space are shown. C and D: Once the foot plate is positioned in the inferior aspect of the spinous process in the midline sublaminar space, the laminotomy proceeds cephalad to the superior aspect of the spinous process. Figure is available in color online only.

as needed. All analgesic doses were calculated according to age and weight. An equianalgesic potency conversion scale was used to convert the various opiates used to oral morphine equivalents (OMEs). ${ }^{5}$ The total OMEs per kilogram per hour used in the first 72 hours after surgery were calculated and compared across groups.

\section{PSM Volumes and Fatty Infiltration}

Preoperative MRI studies and available postoperative MRI studies (from the 1-month follow-up visit or later) were evaluated. Based on the number of available postoperative MRI scans, they were categorized as short-term (1-4 months) or long-term (1-4 years) follow-up images. All MRI studies were anonymized and saved in DICOM format.

OsiriX MD software was used to analyze all imaging data. Sagittal and axial T1- and T2-weighted sequences were used to quantify PSM volume and degree of fat infiltration. The level of the laminar or spinous process defect was defined as the index level. Regions of interest (ROIs) were delineated over the paraspinal musculature. ROIs at the index level and 5 slices above and 5 slices below the index level were collected. Similar measurements were obtained from a single slice in a level rostral to the area of interest for all preoperative and postoperative MRI as an internal control (Fig. 4).

The histogram function was used to determine the pixel value of different tissues, and a segmentation analy- sis (interval 100) was used to quantitate the degree of fat infiltration within the ROIs. Fat and muscle volumes were calculated by multiplying the area of the ROI by the thickness of the corresponding slice. To account for changing muscle volumes related to growth, fat/muscle ratios were obtained. The rate of change for PSM fat infiltration was calculated as follows:

PSM fat infiltration change rate $=[$ (postoperative fat $/$ muscle ratio) - (preoperative fat/muscle ratio)]/ (preoperative fat/muscle ratio)

[Eq. 1]

\section{Statistical Analysis}

The statistical analysis was performed using IBM SPSS (version 22; IBM Corp.) statistical software. The MannWhitney U-test was used to compare pain scores and opiate use across groups. The Pearson correlation coefficient was used for continuous variables, and regression analyses with backward and stepwise selection were used to investigate the effects of sex, age, and group on opiate requirements. Paired 2-sample t-tests were used to compare the fat/muscle ratios calculated from preoperative and short- and longterm follow-up postoperative MRI between groups.

\section{Results}

\section{Population Characteristics}

A total of 125 pediatric patients met the inclusion cri-
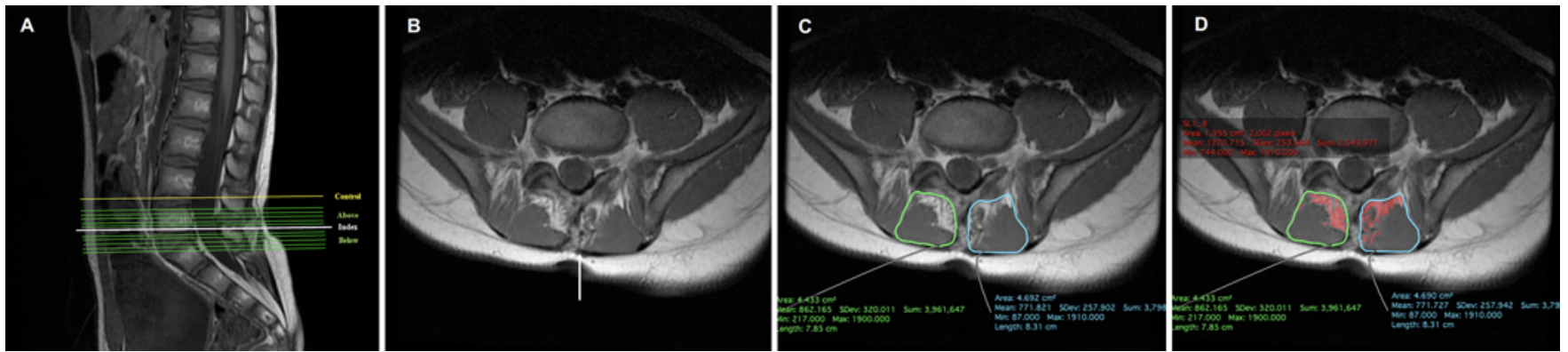

FIG. 4. PSM volume and fat infiltration analysis using lumbar MR images obtained 3 years after surgery. A: Sagittal T1-weighted image showing the level of bony defect (i.e., the index level) (white), segments above and below the index level included in the analysis (green), and the internal control segment (yellow). B: Axial T1-weighted image corresponding to index level. The white arrow points to the partially fused spinous process defect. C: ROI selection for muscle volume determination. D: Segmentation analysis for determination of degree of fat infiltration within the ROls. Figure is available in color online only. 
TABLE 2. Sex distribution according to laminotomy type (all spine levels)

\begin{tabular}{lccc}
\hline & \multicolumn{2}{c}{ No. (\%) According to Sex } & \\
\cline { 2 - 3 } Laminotomy Type & Female & Male & Total No. (\%) \\
\hline Conventional & $44(50.6)$ & $43(49.4)$ & $87(100.0)$ \\
\hline Split & $21(55.3)$ & $17(44.7)$ & $38(100.0)$ \\
\hline Total & 65 & 60 & 125 \\
\hline
\end{tabular}

$p=0.63$ (chi-square test) for distribution of males and females between laminotomy groups.

teria, including 87 patients (44 females, 43 males) in the conventional-laminotomy group (aged 2 months to 19 years) and 38 patients ( 21 females, 17 males) in the splitlaminotomy group (aged 5 months to 17 years) (Table 1).

A total of 117 patients underwent lumbar-level surgery (83 conventional laminotomy, 34 split laminotomy), and 8 patients (4 in each surgical group) underwent thoracic-level surgery. To maintain a homogeneous population, only the patients with a lumbar spinal lipoma who underwent filum terminale sectioning for cord detethering $(n=117)$ were included in the statistical analysis (Table 1).

We found no difference in sex distribution between surgical groups in the initial 125-patient cohort $(\mathrm{p}=0.63)$ (Table 2). When only lumbar-level surgeries were considered, sex and age in the conventional- and split-laminotomy groups also were not significantly different $(\mathrm{p}=0.82$ and 0.28 , respectively) (Tables 3 and 4).

The postoperative follow-up duration ranged from 2 weeks to 4 years (median 2 years). Postoperative MRI studies of only 45 patients (37 after lumbar surgery, 8 after thoracic surgery) were available for analysis.

\section{Surgical Details}

The mean operative times were $81 \pm 35$ minutes in the split-laminotomy group and $116 \pm 50$ minutes in the conventional-laminotomy group $(\mathrm{p}=0.0004)$. We were unable to track estimated blood loss reliably because of variations in documentation styles (e.g., reports of unmeasurable or "minimal" blood loss rather than quantitative data). No blood transfusions were required.

\section{Pain Scores}

The mean daily pain scores on postoperative day 0 (POD0), POD1, and POD2 in the conventional- and split-

TABLE 3. Sex distribution according to laminotomy type (lumbarlevel surgeries only)

\begin{tabular}{lccc}
\hline & \multicolumn{2}{l}{ No. (\%) According to Sex } & \\
\cline { 2 - 3 } Laminotomy Type & Female & Male & Total No. (\%) \\
\hline Conventional & $42(50.6)$ & $41(49.4)$ & $83(100.0)$ \\
\hline Split & $18(52.9)$ & $16(47.1)$ & $34(100.0)$ \\
\hline Total & 60 & 57 & 117 \\
\hline
\end{tabular}

$p=0.82$ (chi-square test) for distribution of males and females between laminotomy groups.
TABLE 4. Age distribution according to laminotomy type (lumbar-level surgeries only)

\begin{tabular}{lcccccc}
\hline \multirow{2}{*}{$\begin{array}{c}\text { Laminotomy } \\
\text { Type }\end{array}$} & $\begin{array}{c}\text { No. of } \\
\text { Patients }\end{array}$ & \multicolumn{5}{c}{ Age (yrs) } \\
\cline { 3 - 7 } & Mean & SD & Median & Min & Max \\
\hline Conventional & 83 & 5.13 & 4.64 & 2.96 & 0.26 & 16.77 \\
\hline Split & 34 & 5.84 & 4.88 & 3.75 & 0.43 & 17.03 \\
\hline
\end{tabular}

$p=0.28$ (Mann-Whitney U-test) for comparison of median ages between laminotomy groups.

laminotomy groups were not significantly different $(\mathrm{p}=$ $0.86,0.27$, and 0.10, respectively) (Table 5 and Fig. 5).

\section{Acute Pain Control: Opioid Consumption}

The daily opioid use was significantly lower in the splitlaminotomy group than in the conventional-laminotomy group on POD0 and POD1 but not on POD2 ( $p=0.01$, 0.01 , and 0.10 , respectively). The total opioid use over the 72-hour postoperative period was significantly lower in the split-laminotomy group $(p=0.0008)$ (Table 6 and Fig. 6).

The total opioid use was not significantly related to age in either the conventional-laminotomy (rho $=0.011, \mathrm{p}=$ 0.92 ) or split-laminotomy (rho $=0.216, \mathrm{p}=0.22$ ) group. The total opioid use over the 72-hour postoperative period was not significantly related to sex for either the conventional- or split-laminotomy group $(\mathrm{p}=0.23$ and 0.20 , respectively). Using total opioid use as the outcome, only the surgical group was highly significant in both the univariate $(\mathrm{p}=0.0009)$ and multivariate $(\mathrm{p}=0.0009)$ analyses (Table 7).

\section{PSM Volumes and Fatty Infiltration}

In the conventional-laminotomy group, the fat/muscle ratios were significantly higher in the short-term (1-4 months) and long-term (1-4 years) follow-up periods than they were before surgery. In the split-laminotomy group, the fat/muscle ratios were not significantly different in the short-term or long-term follow-up periods than they were before surgery (Table 8 and Fig. 7). The rate of PSM fat infiltration was significantly higher in the conventionallaminotomy group than in the split-laminotomy group (Table 9 and Fig. 8).

TABLE 5. Mean daily pain scores according to laminotomy type (lumbar-level surgeries only)

\begin{tabular}{lccccc}
\hline $\begin{array}{c}\text { Laminotomy } \\
\text { Type }\end{array}$ & POD & $\begin{array}{c}\text { No. of } \\
\text { Patients }\end{array}$ & $\begin{array}{c}\text { Mean Pain } \\
\text { Score }\end{array}$ & SD & $\begin{array}{c}\mathrm{p} \\
\text { Value* }\end{array}$ \\
\hline Conventional & 0 & 83 & 1.62 & 1.42 & 0.86 \\
\hline Split & 0 & 34 & 1.49 & 1.07 & \\
\hline Conventional & 1 & 83 & 1.21 & 1.12 & 0.27 \\
\hline Split & 1 & 34 & 1.09 & 1.33 & \\
\hline Conventional & 2 & 42 & 1.51 & 1.16 & 0.10 \\
\hline Split & 2 & 14 & 1.05 & 1.40 & \\
\hline
\end{tabular}

The number of patients was lower for POD2 in both groups due to patient discharges.

* Mann-Whitney U-test. 

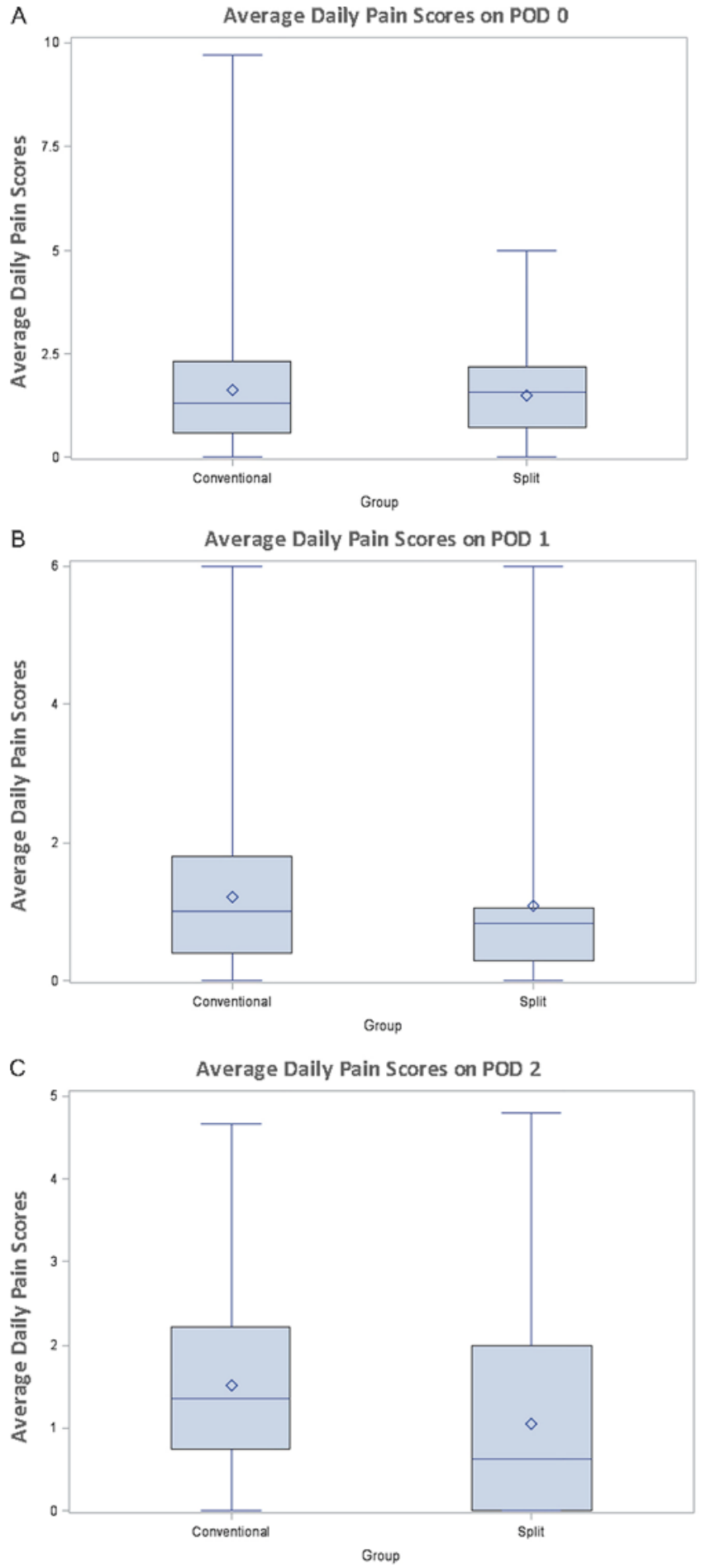

FIG. 5. Mean daily pain scores. Box plots with mean daily pain scores per group on POD0 (A), POD1 (B), and POD2 (C) are shown. The top of each box represents the upper quartile (Q3), the bottom of each box represents the lower quartile (Q1), the line within each box represents the median, each diamond represents the mean, and the lower and upper whiskers represent the minimum and maximum values, respectively. Figure is available in color online only.
TABLE 6. Daily opioid use according to laminotomy type (lumbar-level surgeries only)

\begin{tabular}{lccccc}
\hline $\begin{array}{c}\text { Laminotomy } \\
\text { Type }\end{array}$ & POD & $\begin{array}{c}\text { No. of } \\
\text { Patients }\end{array}$ & $\begin{array}{c}\text { Mean Opioid Use } \\
\text { (OMEs/kg/hr) }\end{array}$ & $\begin{array}{c}\text { SD } \\
\text { Value* }\end{array}$ \\
\hline Conventional & 0 & 83 & 0.0187 & 0.0185 & $0.01 \dagger$ \\
\hline Split & 0 & 34 & 0.0093 & 0.0102 & \\
\hline Conventional & 1 & 83 & 0.0095 & 0.0110 & $0.01 \dagger$ \\
\hline Split & 1 & 34 & 0.0046 & 0.0075 & \\
\hline Conventional & 2 & 42 & 0.0060 & 0.0103 & 0.10 \\
\hline Split & 2 & 14 & 0.0030 & 0.0068 & \\
\hline
\end{tabular}

The number of patients was lower for POD2 in both groups due to patient discharges.

* Mann-Whitney U-test.

$\dagger$ Significant result.

\section{Complications}

Postoperative complications identified included superficial wound dehiscence that did not require intervention, wound infections that required antibiotics, wound infections that required wound revision/washout, CSF leaks with or without associated pseudomeningocele formation, and radicular pain. The overall incidence of complications was not significantly different between the split- and conventional-laminotomy groups $(15.8 \%$ vs $16.1 \%$, respectively; $p=0.08$ ). The incidence of CSF leak-related complications was lower in the split-laminotomy group (2.6\%) than in the conventional-laminotomy group (6.9\%), although this difference did not reach statistical significance $(\mathrm{p}=$ 0.26) (Table 10).

\section{Discussion}

Benefits of the split laminotomy approach in minimizing postoperative pain, muscle atrophy, and subsequent development of spinal instability in the adult population have been reported. . $^{2,4,8,8,12,15,16,21,22}$ Given the unique characteristics of the pediatric spine, the split laminotomy might be even more beneficial in pediatric patients. For instance, although the width of exposure achieved by the split laminotomy limits its application to mostly dorsal/midline approaches and opens the possibility for added challenges during dural closure, the laxity of the pediatric spine might enable more laminar retraction and less risk of laminar fractures in pediatric patients than in adults. ${ }^{3}$ Spinous process fractures can occur if the laminar distractors are deployed too superficially, but these fractures are of no clinical significance. In our experience, the width of exposures was approximately $1 \mathrm{~cm}$ (Fig. 9), and no iatrogenic laminar fractures occurred with the use of the laminar distractors. Although the use of sutures for dural closure is not impossible with this approach, the limited exposure creates a practical challenge to it. In our experience, the use of nonpenetrating titanium clips for dural closure is preferable, because it requires less exposure than does conventional suturing techniques. ${ }^{7}$ The split laminotomy technique can be applied to all spinal segments (Fig. 9) and can be helpful in procedures that require multilevel exposure..$^{10}$ An added theoretical benefit of this technique is that it limits pseu- 
A

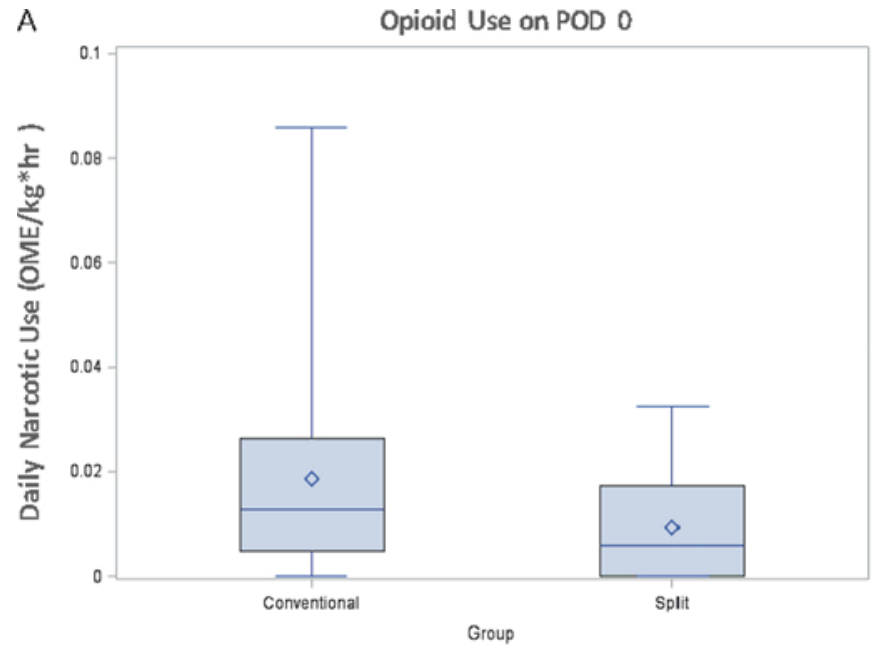

$\mathrm{C}$

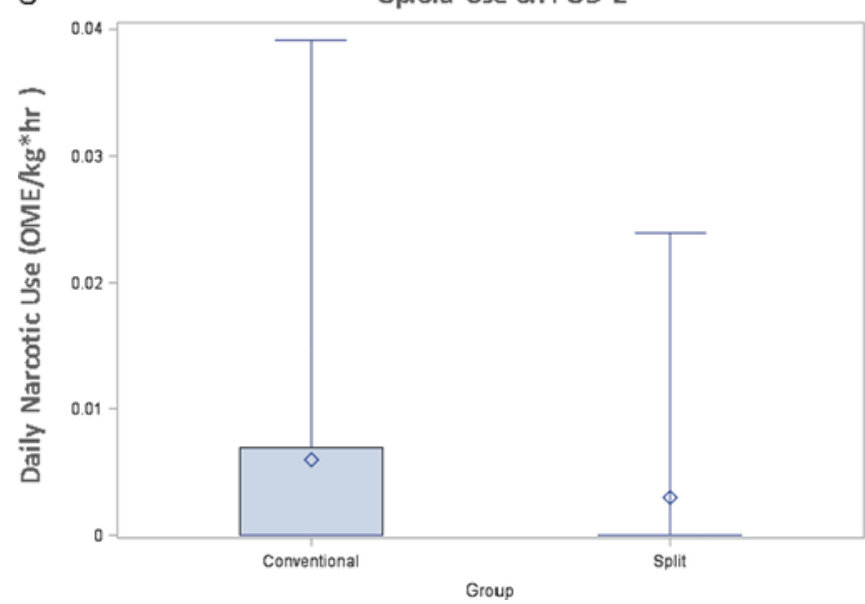

B

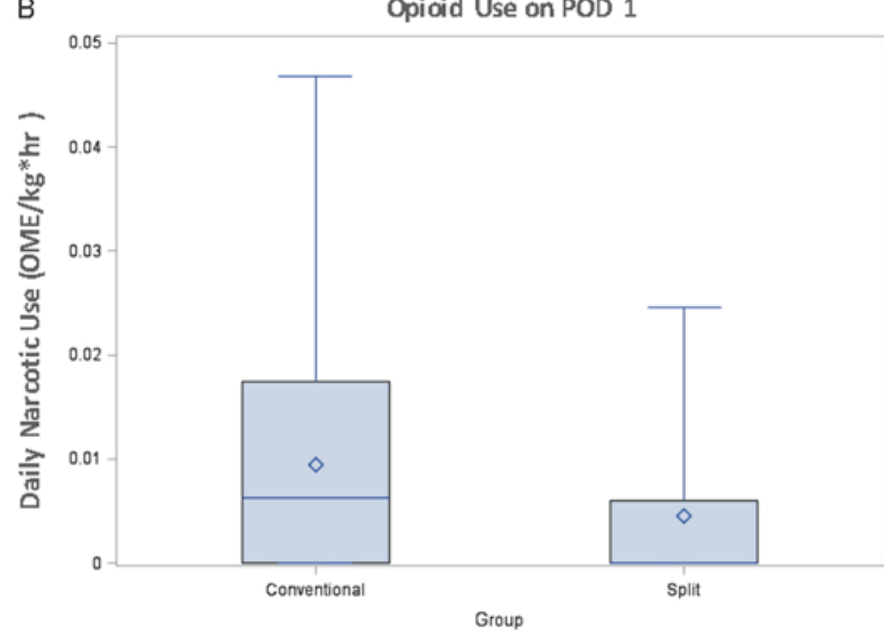

D

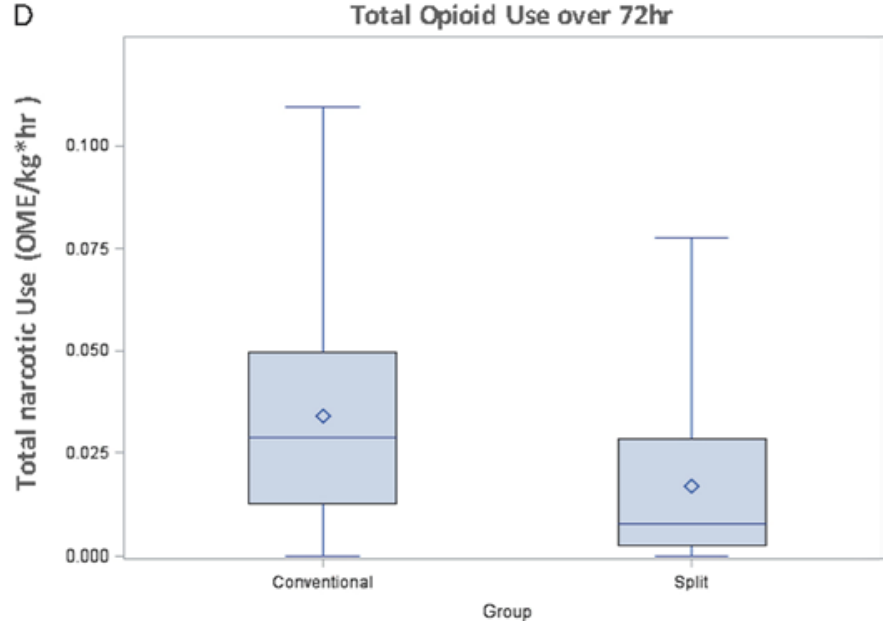

FIG. 6. Daily and total opioid consumption. Box plots with mean daily opioid consumption per group on POD0 (A), POD1 (B), and POD2 (C) and total opioid consumption per group in the 72-hour postoperative period $(p=0.0008)(\mathrm{D})$ are shown. The top of each box represents the upper quartile, the bottom of each box represents the lower quartile (Q1), the line within each box represents the median, each diamond represents the mean, and the lower and upper whiskers represent the minimum and maximum values, respectively. Figure is available in color online only.

domeningocele formation given the preservation of the posterior bony arches and paraspinal musculature (Fig. 9).

In this study, we found no significant difference in mean daily pain scores between the conventional- and split-laminotomy groups. Although this result is not surprising, given the challenges in assessing pain in the pediatric population (e.g., ability to self-report, difficulty dis- tinguishing between pain and anxiety), some other factors could have played a role in this finding. For instance, although the pain scales used were developmentally appropriate, several different scales were used depending on the patient's age and his or her ability to self-report, and some scales relied on observation, which creates a potential for bias related to the perception of actual pain by the nurses

TABLE 7. Evaluation of age, sex, and laminotomy type as predictors of total opioid use

\begin{tabular}{|c|c|c|c|c|}
\hline \multirow[b]{3}{*}{ Variable } & \multicolumn{4}{|c|}{ Outcome (total opioid use) } \\
\hline & \multicolumn{2}{|c|}{ Univariate Model } & \multicolumn{2}{|c|}{ Multivariate Model $(\alpha=0.10)$} \\
\hline & $\mathrm{RR}(95 \% \mathrm{Cl})$ & $p$ Value & $\mathrm{RR}(95 \% \mathrm{Cl})$ & $\mathrm{p}$ Value \\
\hline Age & $1.004(0.97-1.04)$ & 0.82 & & \\
\hline Sex (female vs male) & $0.90(0.62-1.32)$ & 0.60 & & \\
\hline Laminotomy type (split vs conventional) & $0.51(0.34-0.76)$ & $0.0009^{*}$ & $0.51(0.34-0.76)$ & $0.0009^{*}$ \\
\hline
\end{tabular}

$\mathrm{Cl}=$ confidence interval; $\mathrm{RR}=$ risk ratio.

* Significant result. 
TABLE 8. Comparison of fat/muscle ratios across groups in the short-term and long-term follow-up periods (lumbar-level surgeries only)

\begin{tabular}{|c|c|c|c|c|c|c|c|c|}
\hline \multirow{2}{*}{$\begin{array}{c}\text { Laminotomy } \\
\text { Type }\end{array}$} & \multirow[b]{2}{*}{ Follow-Up } & \multirow{2}{*}{$\begin{array}{c}\text { No. of } \\
\text { Patients }\end{array}$} & \multirow{2}{*}{$\begin{array}{c}\text { ROI } \\
\text { Segment }\end{array}$} & \multicolumn{2}{|l|}{ Preop } & \multicolumn{2}{|l|}{ Postop } & \multirow{2}{*}{$\begin{array}{c}\mathrm{p} \\
\text { value }^{*}\end{array}$} \\
\hline & & & & Mean Fat/Muscle Ratio & SE & Mean Fat/Muscle Ratio & SE & \\
\hline \multirow[t]{4}{*}{ Conventional } & \multirow[t]{4}{*}{ Short-term (1-4 mos) } & 8 & Control & 0.174 & 0.105 & 0.096 & 0.026 & 0.4486 \\
\hline & & 8 & Above & 0.125 & 0.034 & 0.252 & 0.038 & $0.0226 \dagger$ \\
\hline & & 8 & Below & 0.180 & 0.028 & 0.312 & 0.034 & $0.0052 \dagger$ \\
\hline & & 8 & All & 0.156 & 0.031 & 0.284 & 0.035 & $0.0107 \dagger$ \\
\hline \multirow[t]{4}{*}{ Split } & \multirow[t]{4}{*}{ Short-term (1-4 mos) } & 3 & Control & 0.179 & 0.042 & 0.177 & 0.077 & 0.9807 \\
\hline & & 3 & Above & 0.174 & 0.038 & 0.184 & 0.037 & 0.3921 \\
\hline & & 3 & Below & 0.193 & 0.044 & 0.197 & 0.037 & 0.6749 \\
\hline & & 3 & All & 0.179 & 0.029 & 0.190 & 0.031 & 0.3352 \\
\hline \multirow[t]{4}{*}{ Conventional } & \multirow[t]{4}{*}{ Long-term (1-4 yrs) } & 9 & Control & 0.036 & 0.010 & 0.080 & 0.016 & $0.0187 \dagger$ \\
\hline & & 9 & Above & 0.114 & 0.022 & 0.250 & 0.022 & $0.0030 \dagger$ \\
\hline & & 9 & Below & 0.082 & 0.024 & 0.255 & 0.026 & $0.0005 \dagger$ \\
\hline & & 9 & All & 0.100 & 0.020 & 0.258 & 0.017 & $0.0002 \dagger$ \\
\hline \multirow[t]{4}{*}{ Split } & \multirow[t]{4}{*}{ Long-term (1-4 yrs) } & 6 & Control & 0.122 & 0.022 & 0.122 & 0.032 & 0.9872 \\
\hline & & 6 & Above & 0.194 & 0.029 & 0.208 & 0.032 & 0.7076 \\
\hline & & 6 & Below & 0.244 & 0.026 & 0.243 & 0.034 & 0.9691 \\
\hline & & 6 & All & 0.224 & 0.019 & 0.225 & 0.029 & 0.9687 \\
\hline
\end{tabular}

* Paired 2-sample t-test.

$\dagger$ Significant result.

A

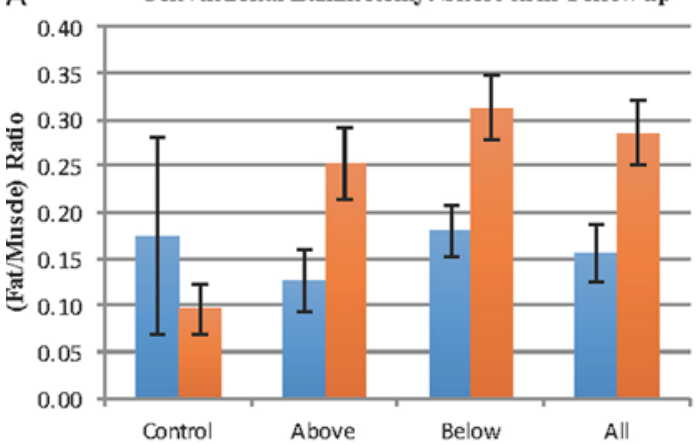

ROI Segment

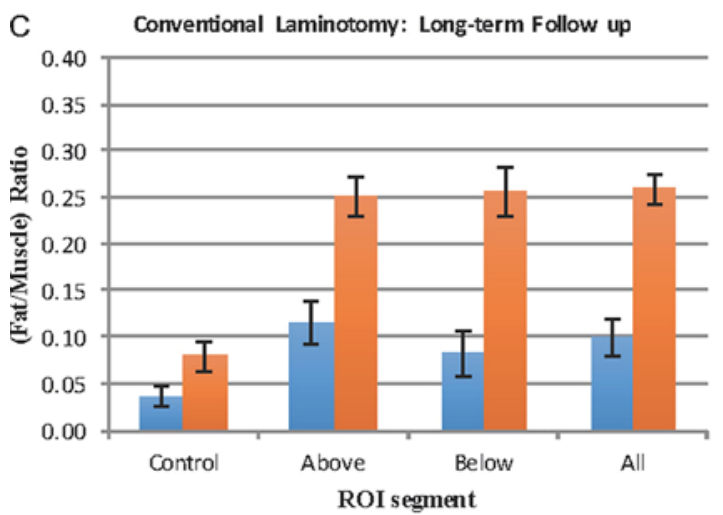

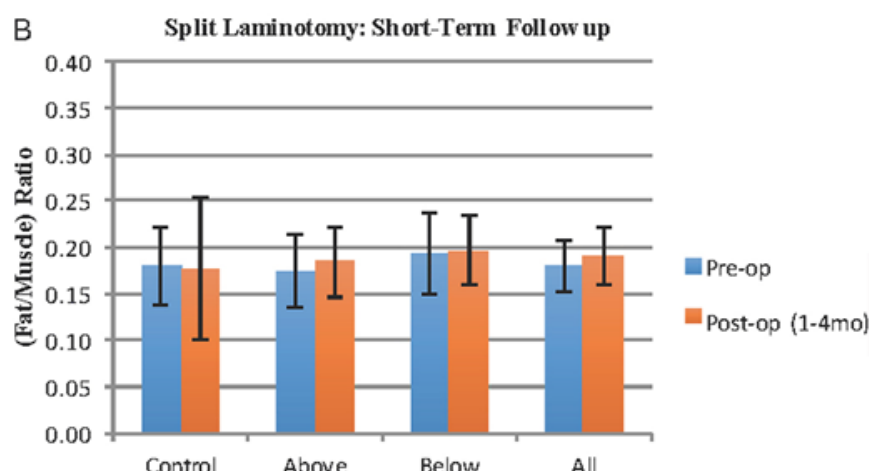

ROI Segment

D Split Laminotomy: Long-Term Follow up

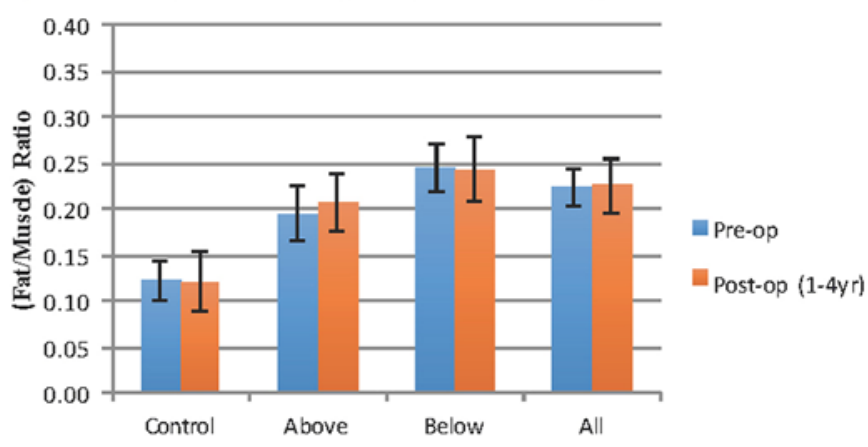

ROI Segment

FIG. 7. PSM fat infiltration in the short-term ( $A$ and $B$ ) and long-term ( $C$ and $D)$ follow-up periods. The y-axes represent the mean fat/muscle ratio, and the x-axes represent the segments used for ROI analysis in relation to the index level. The fat/muscle ratios were significantly higher in the short-term (1-4 months) and long-term (1-4 years) follow-up periods than they were before surgery in the conventional-laminotomy group (A and $\mathbf{C}$, respectively). In the split-laminotomy group, the fat/muscle ratios were not significantly different in the short-term or long-term follow-up periods than they were before surgery ( $B$ and $D$, respectively). Figure is available in color online only. 
TABLE 9. Rate of PSM fat infiltration across groups (lumbar-level surgeries only)

\begin{tabular}{|c|c|c|c|c|c|c|}
\hline \multirow[b]{2}{*}{ Follow-Up } & \multirow[b]{2}{*}{ ROI Segment } & \multicolumn{2}{|c|}{ Conventional-Laminotomy Group $(n=9)$} & \multicolumn{2}{|c|}{ Split-Laminotomy Group $(n=6)$} & \multirow[b]{2}{*}{ p Value* } \\
\hline & & Mean Fat Infiltration Ratio & SE & Mean Fat Infiltration Ratio & SE & \\
\hline \multirow{4}{*}{$\begin{array}{l}\text { Long-term } \\
\text { (1-4 yrs) }\end{array}$} & Control & 3.102 & 1.431 & 0.066 & 0.275 & 0.113 \\
\hline & Above & 1.999 & 0.588 & 0.154 & 0.233 & $0.029 \dagger$ \\
\hline & Below & 4.961 & 1.826 & -0.001 & 0.118 & $0.048 \dagger$ \\
\hline & All & 2.406 & 0.590 & 0.024 & 0.161 & $0.007 \dagger$ \\
\hline
\end{tabular}

* Paired 2-sample t-test.

$\dagger$ Significant result.

and parents. Also, different charting systems (paper and electronic) were used in the 2008-2015 period (electronic medical records were adopted in 2012), which could have led to systematic differences in the recording of patient pain scores (e.g., more frequent entries with the electronic medical record system).

Our assessment of opioid medication use revealed a statistically significant difference between the groups even though our comparison of recorded pain scores did not, which suggests that assessing opioid use is a more objective means of assessing postoperative pain control in this population. The daily opioid use decreased for both groups over the 72-hour postoperative period, and it was lower for those in the split-laminotomy group on each day; statistical significance was achieved for POD0 and POD1 but not for POD2. This finding is likely related to the large number of patients discharged by POD2 (49\% and 58\% for the conventional- and split-laminotomy groups, respectively). Given that one of the criteria for discharge was evidence of adequate pain control, it seems logical to deduce that patients with less postoperative pain or better pain control would be discharged earlier, which affects their overall

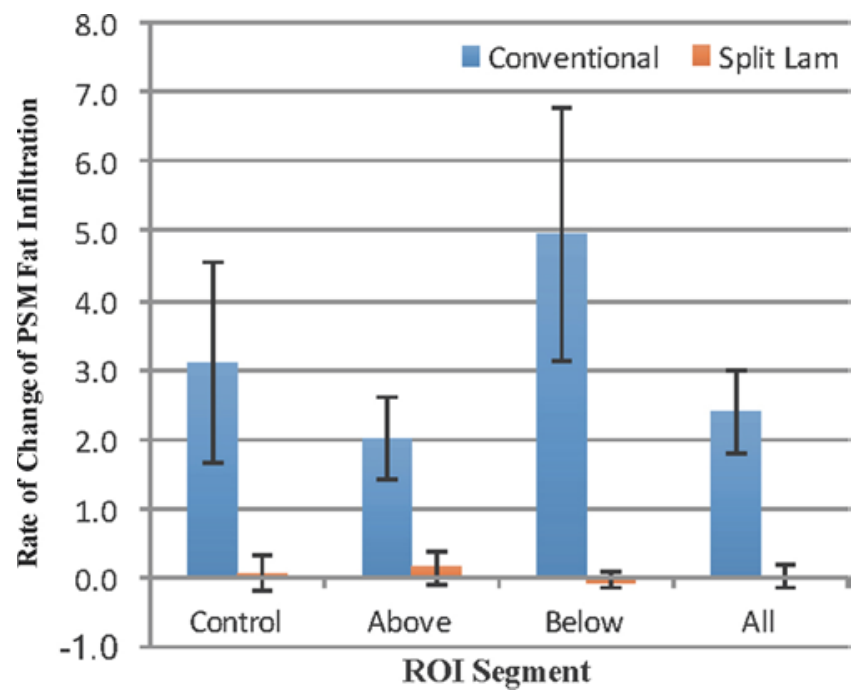

FIG. 8. Rates of change for PSM fat infiltration in the long-term (1-4 years) follow-up period. A bar graph depicts differences in the rates of PSM fat infiltration for the conventional-laminotomy and split-laminotomy (Lam) groups. The $\mathrm{x}$-axis variables represent the segments used for ROI analysis in relation to the index level. Figure is available in color online only. length of stay. However, other factors, such as variability in perioperative management, could have influenced the overall hospital length of stay. For example, postoperative activity restrictions to flat bedrest ranged from 24 to 48 hours depending on clinical concern for spinal fluid leak and surgeon preference. Additional differences, such as decisions or the need to treat other conditions (not related to their surgery) during the same inpatient stay, influenced the overall length of stay for some patients, which makes this variable less useful in comparisons. Overall, the total opioid use over the first 72 hours after surgery was significantly lower for patients in the split-laminotomy group than for those in the conventional-laminotomy group, which is consistent with results discussed in previous reports of studies in adults. ${ }^{6,8,22}$

Previous studies in the adult population have established that procedures that strip muscle off the bone, such as the conventional laminotomy and laminectomy, can damage the neurovascular supply to the muscle and lead eventually to muscle atrophy and fat infiltration. ${ }^{9,14,17,18,23,24}$ Muscle atrophy and PSM fat infiltration have, in turn, been linked to the incidence of chronic back pain..$^{17,18,24}$ In our study, para-

TABLE 10. Incidence of complications according to laminotomy type (lumbar-level surgeries only)

\begin{tabular}{|c|c|c|c|}
\hline \multirow[b]{2}{*}{ Parameter } & \multicolumn{2}{|c|}{ No. of Patients (\%) } & \multirow[b]{2}{*}{$\begin{array}{c}p \\
\text { Value* }\end{array}$} \\
\hline & $\begin{array}{l}\text { Conventional } \\
\text { Laminotomy }\end{array}$ & $\begin{array}{c}\text { Split } \\
\text { Laminotomy }\end{array}$ & \\
\hline No. of patients & 87 & 38 & \\
\hline \multicolumn{4}{|l|}{ Complications } \\
\hline Superficial wound dehiscence & 4 & 2 & \\
\hline $\begin{array}{l}\text { Wound infection, required } \\
\text { antibiotics }\end{array}$ & 2 & 1 & \\
\hline $\begin{array}{l}\text { Wound infection, required } \\
\text { washout }\end{array}$ & 1 & 1 & \\
\hline CSF leak, improved w/ bedrest & 1 & 0 & \\
\hline CSF leak, required repair & 4 & 1 & \\
\hline $\begin{array}{l}\text { Pseudomeningocele, required } \\
\text { repair }\end{array}$ & 1 & 0 & \\
\hline Back pain/radicular symptoms & 1 & 1 & \\
\hline Total complications & $14(16.1)$ & $6(15.8)$ & 0.08 \\
\hline $\begin{array}{l}\text { Total CSF leak-related complica- } \\
\text { tions }\end{array}$ & $6(6.9)$ & $1(2.6)$ & 0.26 \\
\hline
\end{tabular}

* Paired 2-sample t-test. 

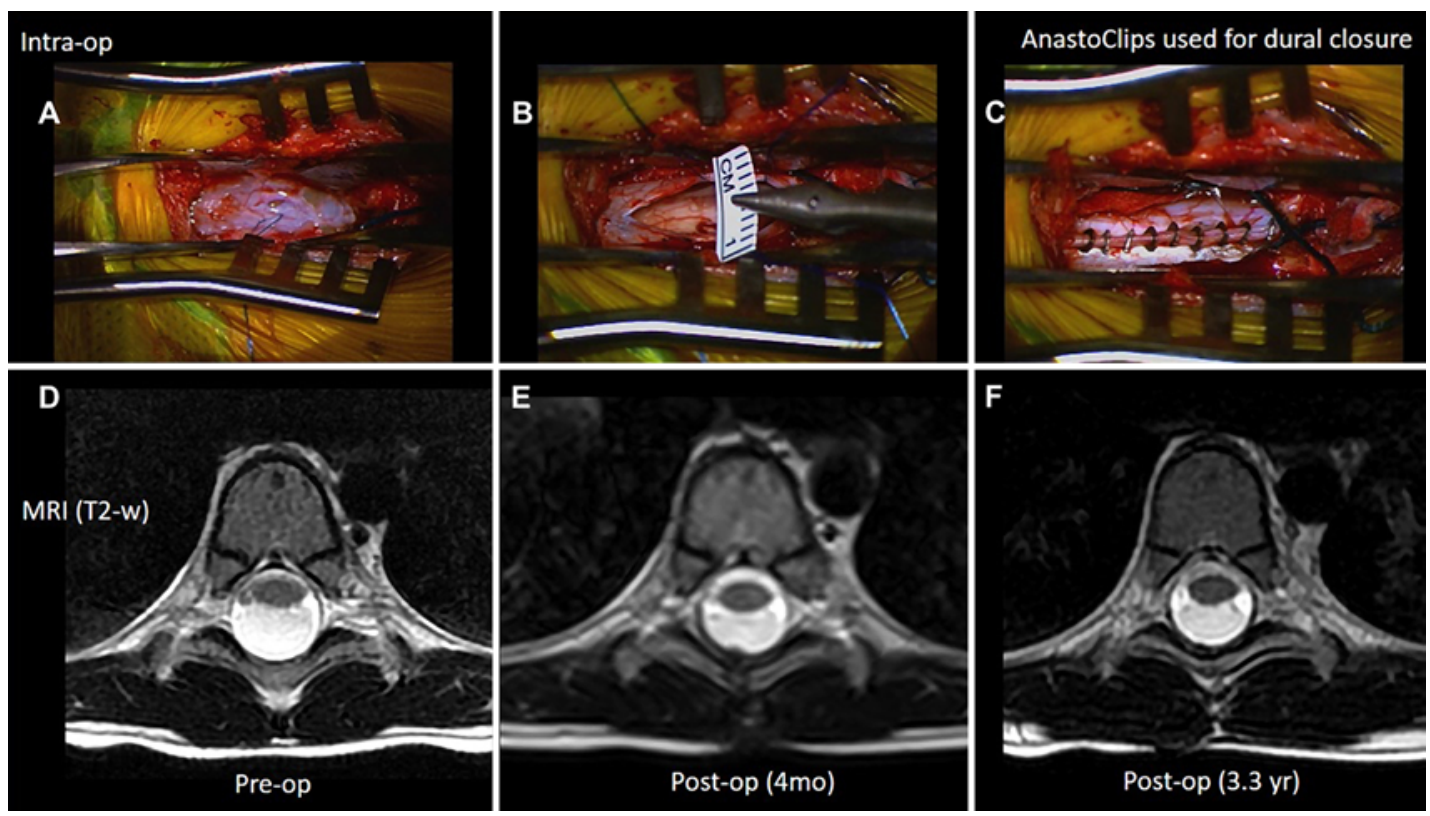

FIG. 9. Two-level thoracic (T8-9) split laminotomy for arachnoid cyst resection. Intraoperative images show the exposed arachnoid cyst $(\mathbf{A})$, dural opening and spinal cord after removal and ruler showing the approximately $1-\mathrm{cm}$ width of exposure (B), and dural closure using AnastoClips ${ }^{7}(\mathbf{C})$. Also shown are thoracic spine T2-weighted MR images showing the arachnoid cyst ventrally displacing the cord and an intact spinous process (D), the decompressed arachnoid cyst 4 months after surgery and evidence of the split laminotomy defect within the spinous process $(\mathbf{E})$, and intact laminar arches with a healed spinous process and no evidence of muscle atrophy 3.3 years after surgery $(\mathbf{F})$. Figure is available in color online only.

spinal fat/muscle ratios were indeed significantly higher in the conventional-laminotomy group at the short-term (1-4 months) and long-term (1-4 years) follow-up visits than they were before surgery. In contrast, no such difference was seen in the split-laminotomy group (Table 8).

Previous studies in adults also focused on the rate of change of PSM atrophy. ${ }^{9,14,18,23}$ However, to account for continued muscle growth common in the pediatric population, we assessed the rate of change of PSM fat infiltration (Eq. 1). This percent change was significantly lower in the split-laminotomy group than in the conventional-laminotomy group at the long-term follow-up visit (Table 9).

Overall, we found no statistically significant difference in the incidence of complications between the 2 groups. However, we found a lower incidence of CSF leak-related complications in the split-laminotomy group (2.6\%) than in the conventional-laminotomy group (6.9\%) (Table 10). Cases of wound breakdown and wound infections were noticed to be more common in patients who were incontinent. The overall incidence of complications was similar to that in a previous report of pediatric patients who underwent division of the filum terminale. ${ }^{13}$

This study had several limitations, some of which are an inherent part of retrospective studies. For instance, although the number of lumbar-level cases for comparison of outcomes between surgical groups was sufficient to reach statistical significance, the number of controlled thoracic-level cases was minimal, and we had no isolated cervical-level cases for evaluation. Follow-up times were variable, ranging from 2 weeks to 4 years, and no standardized follow-up imaging protocols were followed (i.e., routine postoperative MRI scans and spine radiographs were not available for all patients, and not all imaging studies were acquired in the same institution or with the same scanner), which precluded a proper assessment of the development of spinal instability, spinal deformity, chronic pain, etc. In addition, some differences might have resulted from practice variables related to the surgeons, because not all surgeons performed all surgeries (i.e., only 1 surgeon used the split laminotomy approach, whereas 3 surgeons used the conventional laminotomy approach).

\section{Conclusions}

To our knowledge, this study represents the largest series to date of pediatric patients who underwent split laminotomy. Our results reinforce the short-term benefit of split laminotomy previously identified in adult studies in minimizing acute postoperative pain and the long-term benefits of decreasing muscle atrophy and fatty degeneration, which are known to be associated with the development of chronic pain and spinal instability. Additional efforts to assess long-term effects in the development of chronic pain, spinal instability, and spinal deformity are still necessary, especially in cases of multilevel exposure.

\section{Acknowledgments}

We thank contributors Pippa Simpson, PhD, and Raymond Hoffmann, PhD, for their assistance with statistical analysis, supported by the National Center for Advancing Translational Sciences, National Institutes of Health (award UL1TR001436); Teresa Kelly, MD, for valuable discussions and suggestions regarding resources within our radiology department; Marjorie Bessette 
Baker for her technical assistance in anonymization and transfer of imaging data for analysis; and Danielle Buetow for her instrumental assistance with coordination and submission of required materials for IRB review, approval, and project continuation. The content of this article is solely the responsibility of the authors and does not necessarily represent the official views of the National Institutes of Health.

\section{References}

1. Babl FE, Crellin D, Cheng J, Sullivan TP, O'Sullivan R, Hutchinson A: The use of the faces, legs, activity, cry and consolability scale to assess procedural pain and distress in young children. Pediatr Emerg Care 28:1281-1296, 2012

2. Banczerowski P, Vajda J, Veres R: Exploration and decompression of the spinal canal using split laminotomy and its modification, the "archbone" technique. Neurosurgery $62(5$ Suppl 2):ONS432-ONS441, 2008

3. Bognár L, Madarassy G, Vajda J: Split laminotomy in pediatric neurosurgery. Childs Nerv Syst 20:110-113, 2004

4. Cho DY, Lin HL, Lee WY, Lee HC: Split-spinous process laminotomy and discectomy for degenerative lumbar spinal stenosis: a preliminary report. J Neurosurg Spine 6:229_ 239, 2007

5. Chung KC, Barlev A, Braun AH, Qian Y, Zagari M: Assessing analgesic use in patients with advanced cancer: development of a new scale - the Analgesic Quantification Algorithm. Pain Med 15:225-232, 2014

6. Kanbara S, Yukawa Y, Ito K, Machino M, Kato F: Surgical outcomes of modified lumbar spinous process-splitting laminectomy for lumbar spinal stenosis. J Neurosurg Spine 22:353-357, 2015

7. Kaufman BA, Matthews AE, Zwienenberg-Lee M, Lew SM: Spinal dural closure with nonpenetrating titanium clips in pediatric neurosurgery. J Neurosurg Pediatr 6:359-363, 2010

8. Kim K, Isu T, Sugawara A, Matsumoto R, Isobe M: Comparison of the effect of 3 different approaches to the lumbar spinal canal on postoperative paraspinal muscle damage. Surg Neurol 69:109-113, 2008

9. Min SH, Kim MH, Seo JB, Lee JY, Lee DH: The quantitative analysis of back muscle degeneration after posterior lumbar fusion: comparison of minimally invasive and conventional open surgery. Asian Spine J 3:89-95, 2009

10. Nguyen HS, Lew S: Extensive multilevel split laminotomy for debulking a cervicothoracolumbar nondysraphic intramedullary spinal-cord lipoma in a 2-month-old infant. Pediatr Neurosurg 52:189-194, 2017

11. Nilsson S, Finnström B, Kokinsky E: The FLACC behavioral scale for procedural pain assessment in children aged 5-16 years. Paediatr Anaesth 18:767-774, 2008

12. Nomura H, Yanagisawa Y, Arima J, Oga M: Clinical outcome of microscopic lumbar spinous process-splitting laminectomy: clinical article. J Neurosurg Spine 21:187-194, 2014

13. Ostling LR, Bierbrauer KS, Kuntz C IV: Outcome, reoperation, and complications in 99 consecutive children operated for tight or fatty filum. World Neurosurg 77:187-191, 2012

14. Pezolato A, de Vasconcelos EE, Defino HL, Nogueira-Barbosa MH: Fat infiltration in the lumbar multifidus and erector spinae muscles in subjects with sway-back posture. Eur Spine J 21:2158-2164, 2012

15. Rajasekaran S, Thomas A, Kanna RM, Shetty AP: Lumbar spinous process splitting decompression provides equivalent outcomes to conventional midline decompression in degenerative lumbar canal stenosis: a prospective, randomized controlled study of 51 patients. Spine (Phila Pa 1976) 38:1737-1743, 2013
16. Shetty AP, Kanna RM, Avadhani A, Rajasekaran S: Lumbar spinous process split decompression. Eur Spine J 19:357358,2010

17. Sihvonen T, Herno A, Paljärvi L, Airaksinen O, Partanen J, Tapaninaho A: Local denervation atrophy of paraspinal muscles in postoperative failed back syndrome. Spine (Phila Pa 1976) 18:575-581, 1993

18. Teichtahl AJ, Urquhart DM, Wang Y, Wluka AE, Wijethilake P, O'Sullivan R, et al: Fat infiltration of paraspinal muscles is associated with low back pain, disability, and structural abnormalities in community-based adults. Spine J 15:15931601,2015

19. von Baeyer CL: Children's self-reports of pain intensity: scale selection, limitations and interpretation. Pain Res Manag 11:157-162, 2006

20. von Baeyer CL, Jaaniste T, Vo HLT, Brunsdon G, Lao HC, Champion GD: Systematic review of self-report measures of pain intensity in 3-and 4-year-old children: bridging a period of rapid cognitive development. J Pain 18:1017-1026, 2017

21. Watanabe K, Hosoya T, Shiraishi T, Matsumoto M, Chiba K, Toyama Y: Lumbar spinous process-splitting laminectomy for lumbar canal stenosis. Technical note. J Neurosurg Spine 3:405-408, 2005

22. Watanabe K, Matsumoto M, Ikegami T, Nishiwaki Y, Tsuji T, Ishii K, et al: Reduced postoperative wound pain after lumbar spinous process-splitting laminectomy for lumbar canal stenosis: a randomized controlled study. J Neurosurg Spine 14:51-58, 2011

23. Woodham M, Woodham A, Skeate JG, Freeman M: Longterm lumbar multifidus muscle atrophy changes documented with magnetic resonance imaging: a case series. J Radiol Case Rep 8:27-34, 2014

24. Yasuoka S, Peterson HA, MacCarty CS: Incidence of spinal column deformity after multilevel laminectomy in children and adults. J Neurosurg 57:441-445, 1982

\section{Disclosures}

The authors report no conflict of interest concerning the materials or methods used in this study or the findings specified in this paper.

\section{Author Contributions}

Conception and design: Lew, Arocho-Quinones. Acquisition of data: Lew, Arocho-Quinones, Kolimas. Analysis and interpretation of data: Lew, Arocho-Quinones, LaViolette. Drafting the article: Arocho-Quinones. Critically revising the article: Lew, Arocho-Quinones, Kaufman, Foy, Zwienenberg. Reviewed submitted version of manuscript: Lew, Arocho-Quinones, Kaufman, Foy, Zwienenberg. Statistical analysis: Arocho-Quinones, LaViolette. Administrative/technical/material support: Lew, ArochoQuinones. Study supervision: Lew. Principal investigator: Lew.

\section{Supplemental Information \\ Videos}

Video 1. https://vimeo.com/250630443.

\section{Previous Presentations}

Portions of this work were presented in abstract/poster form at the 44th Annual Meeting of the American Association of Neurological Surgeons/Congress of Neurological Surgeons Section on Pediatric Neurological Surgery, Seattle, WA, December 8, 2015.

\section{Correspondence}

Sean M. Lew: Medical College of Wisconsin, Children's Hospital of Wisconsin, Milwaukee, WI. slew@mcw.edu. 